\title{
Editorial from the Managing Editor
}

The first copies of The Journal of Chiropractic Education were sent to interested educators and chiropractic institutions 19 years ago. The brainchild of Grace Jacobs, DA, the journal was originally printed by mimeograph and, by today's standards, had more of the appearance of a newsletter than a journal. Much can be said about her aspiration and hard work. Dr. Jacobs nurtured and developed the journal for 10 years, brought it into a traditional journal format, and thoroughly inculcated it into the annual Association of Chiropractic Colleges (ACC) Annual Educational Conference. Her efforts are remembered by several of our veteran educators, but may be unknown by some. We pause to recognize her many years of dedication to improving chiropractic education.

It is from Robert Ward, DC, that I assume the helm as managing editor. Serving the journal from 1998 through mid-year 2006, Dr. Ward has been instrumental in raising the quality of scholarship published in the journal through an enhanced peer-review process, thought-provoking editorials, and pioneering the use of a new editorial system. During his leadership, the journal has grown in sophistication and quality. Thanks to his efforts, the journal now reaches a larger audience than ever. It is our good fortune that Dr. Ward has agreed to continue to serve the journal as a peer reviewer and assist with a smooth transition of managing editors.

I am honored to be named the third managing editor of the journal and I am thankful for the immense efforts of my predecessors to manage and nurture this periodical. I am grateful to Drs. Jacobs and Ward for their many years of selfless service to the journal and the profession. They have set the bar high and, when the time comes for me to pass the editorship on to a new editor, I hope to be able to look back and see that I have made as worthy a contribution as they.

Commensurate with a change in leadership, readers will see some changes with the journal. To begin, the journal now processes manuscripts solely in electronic format in order to decrease the time required for peer review and publication processes. This will provide authors with a more efficient and rapid submissionto-decision experience. Authors can acquire the new instructions for authors and the new assignment of copyright form at the journal's new website

(www.journalchiroed.com). I am excited to announce that our new website also is the home for back issues of The Journal of Chiropractic Education (volumes 13-20) in electronic format. Volumes 1-11 will be loaded to the website as they are scanned. Having The Journal of Chiropractic Education available online brings us up to standard with the publishing world and provides greater dissemination of the scholarship of chiropractic education. Now, anyone in the world can access the full journal contents for no cost, making The Journal of Chiropractic Education an open access journal. Many journals require that authors pay a fee to publish in an open access journal; authors can rest assured that we have no such plans. Those who know me are aware of my biases toward preserving the history of chiropractic; 
readers will note that our former editors are now noted on the journal's masthead. Lastly, a new section called Educational Research in Action debuts in this issue and provides evidence-based educational tools and information for educators. This section will bring even more useable information to our readers.

Many folks have assisted me in my first few months as managing editor. I would like to thank Dr. Reed Phillips for a smooth transition and the ACC and our publisher, Data Trace, for agreeing to allow our back issues to be published online at no cost. Acknowledgments are also due to many of my friends and colleagues who have provided suggestions for improvements to the journal or requested that certain practices be maintained.

I look forward to serving the readership of The Journal of Chiropractic Education. Should you have a comment, criticism, or question, I hope that you will e-mail me personally or submit a letter to the editor.

Bart Green, DC, MSEd, DACBSP Managing Editor 